\title{
HUBUNGAN ANTARA JARAK, TINGGI SIKU DENGAN TEMPAT DUDUK DAN KELUHAN MOSCULOSKELETAL PADA PEKERJA BAGIAN JUMBO BAG DI PERUSAHAAN PRODUKSI PLASTIK TAHUN 2013 \\ Doni Dwi Kristanto, Demes Nurmayanti, Ferry Kriswandana
}

\begin{abstract}
Sewing machine operators are at high risk of developing musculoskeletal disorders due to working in seated position at poorly designed workstations, performing the same operation during the entire course of the workday. The poor postures resulting from these conditions, combined with highly repetitive and time-pressured work may result in high incidence of work-related musculoskeletal disorders among sewing machine operators. The main objective of this study was to analyze the relationship between the distance from elbows to seat pan and musculoskeletal complaints among sewing machine operators in a plastic manufacturing company.

This is ananalytical research using cross sectional approach. The total number of subjects under study were 74 subjects out of a total of 286 workers drawn by random sampling.

The study discovered that respondents were subjected to not ergonomics elbow position as many as $89.6 \%$, with mild complaints $50 \%$ and serious complaints was $50 \%$. The chi square test proved that there was a relationship between the distance of elbow to the seat with mosculoskeletal complaints.

The result of this study concluded that musculoskeletal complaints are prevalent among sewing workers. Therefore, it is recommended that the company should provide adjustable chairs, allow frequent short breaks and adequate work spaces to all workers in order to reduce future musculoskeletal complaints.
\end{abstract}

\section{Keywords $\quad$ : Elbow Distance, Mosculoskeletal Complaints}

\section{PENDAHULUAN \\ Latar Belakang}

Tenaga kerja mempunyai hak yang diatur pada Undang-Undang Ketenagakerjaan No. 13 Th. 2003, menegaskan tenaga kerja berhak memperoleh perlindungan atas keselamatan dan kesehatan kerja. Perusahaan mengupayakan kesehatan kerja pada tenaga kerja untuk mencegah penyakit yang ditimbulkan oleh produk perusahaan tersebut. Upaya kesehatan kerja yang dilakukan perusahaan adalah upaya promotif yaitu meningkatkan kesehatan tenaga kerja, dimana dengan tenaga yang sehat akan diperoleh produktivitas kerja yang tinggi.(Notoadmojo, 2003)

Ergonomi adalah satu kesatuan ilmu yang meliputi antropometri, biometrika, fisiologi kerja, hygiene perusahaan dan kesehatan kerja, dimana dalam ruang lingkup terdiri dari penyesuaian suatu pekerjaan terhadap tenaga kerja yang bekerja sehingga timbul timbal balik untuk efisiensi dan kenyamanan dalam bekerja yang dilihat dari anatomi, fissiologi, psikologi, engineering, manajemen, dan desain / perancangan(Suma'mur, 2009 dan Nurmianto, 1996). Ergonomi dapat mengurangi beban kerja, dengan evaluasi fisiologis, psikologis atau cara tak langsung, beban kerja dapat diukur dengan dianjurkan memodifikasi yang disesuaikan dengan kapasitas kerja dengan beban kerja serta beban tambahan. Tujuan utama penerapan ergonomi adalah untuk menjamin kesehatan, sehingga dapat meningkatkan produktivitas (Gempur, 2004). Prinsip ergonomic adalah sesuatu mudah dijangkau, bekerja dengan tinggi, bekerja dengan postur yang sesuai, mengurangi tenaga yang berlebihan, meminimalkan keletihan/kepenatan, menciptakan lingkungan yang menyenangkan, pencahayaan dan temperatur yang tepat serta mengecilkan getaran (Nico dias 2013).

Ilmu kesehatan dan ergonomi menganjurkan bahwa tenaga kerja dalam melakukan pekerjaan dapat dilakukan dengan cara duduk, hal ini di karenakan rendahnya tegangan pada kaki, sikap tak alami dapat dihindari, konsumsi energi dapat terkurangi, kebutuhan peredaran darah hanya sedikit (Suyatno, 1985). Desain kursi dan ketinggian meja untuk bekerja dianjurkan sesuai dengan jenis pekerjaannya menurut (Suma'mur, 2009 dan Nurmianto, 1996). Tinggi tempat duduk dapat di atur disesuaikan dengan papan injakan kaki yang disesuai dengan ukuran tinggi lutut, sedangkan posisi paha datar. Lebar alas duduk tidak kurang dari lebar terbesar ukuran antropometri pinggul misalnya lebih dari $40 \mathrm{~cm}$. Tinggi meja kerja jika dataran, maka tinggi siku dinyatakan sebagai dataran 0 (nol).

Keluhan mosculoskeletal merupakan keluhan yang dirasakan pada seseorang yang hanya dirasakan oleh orang itu saja. Beberapa keluhan mosculoskeletal meliputi kesemutan disebabkan setelah anestesi atau kurangnya sirkulasi darah ke seluruh tubuh (Andryani 2012), nyeri pinggang diakibatkan bergesernya 
bantalan tulang belakang/ Herniated Nucleus Pulposus yang menyebabkan keluarnya inti dari bantalan tulang, hal tersebut membuat penekanan pembuluh darah balik, kantung saraf maupun saraf itu sendiri. Iritasi akibat penekanan dari bantalan tulang tersebut menyebabkan rasa nyeri sampai kelumpuhan dari saraf yang tertekan. (www.infokesehatan.com, penyebab sakit pinggang). dan pegal bahu yang disebabkan oleh nyeri local/ nyeri saat menggerakkan lengan(www.wikipedia.com)

Perusahaan produksi plastik ini merupakan perusahaan yang membuat bag atau karung berukuran besar, yang diproduksi pada bagian divisi jumbo bag. Jumbo bag adalah karung yang berukuran besar untuk menyimpan dan mengangkut berbagai produk butiran, bubuk, atau serpihan misalnya semen, pasir, pupuk, resin plastic dan sebagainya. Jumbo bag terbuat dari anyaman polypropylene dan biasanya memilikki ukuran sesuai dengan jenis produk yang akan digunakan.

Hasil survey pendahuluan, didapatkan bahan meja dan kursi terbuat dari kayu dengan ukuran tinggi kursi $45 \mathrm{~cm}$, tinggi meja $80 \mathrm{~cm}$, sandaran kursi $36 \times 24 \mathrm{~cm}$, lebar alas tempat duduk $38 \times 38 \mathrm{~cm}$ dengan satu ukuran, dalam artian semua pekerja menggunakan ukuran meja kursi yang sama dan tidak dapat di sesuaikan tingginya baik meja maupun kursi dengan kenyamanan pekerja dalam bekerja, pada saat memproduksi produk jumbo bag tersebut. Tenaga kerja dalam menjahit jumbo bag membutuhkan waktu 8 jam yang terus menerus dalam posisi duduk.

Berdasarkan laporan dari pengelola $\mathrm{K} 3$ (Keselamatan dan Kesehatan Kerja) Perusahaan produksi plastik bahwa ada keluhan kesakitan tenaga kerja yang berhubungan dengan fasilitas yang digunakan tenaga kerja pada saat proses menjahit. Dampak dari fasilitas yang tidak memadai tersebut diantaranya yaitu kesemutan, nyeri pinggang, pegal bahu.

\section{Tujuan}

Untuk mengkaji hubungan jarak tinggi siku pekerja dengan kursi yang digunakan terhadap keluhan moskuloskeletal pada pekerja Perusahaan produksi plastik divisi jumbo bag tahun 2013.

\section{METODE PENELITIAN}

Jenis penelitian adalah cross sectional yaitu melakukan satu kali pengamatan dalam jangka waktu tertentu. Populasi dalam penelitian adalah pekerja yang melakukan pekerjaan menjahit di Perusahaan produksi plastik Divisi Jumbo Bag sebanyak 286 tenaga kerja, sedangkan sampel penelitian berjumlah 74 tenaga kerja. Data yang diperoleh dari hasil observasi, pengukuran, dan wawancara diolah dalam bentuk table dan dianalisis menggunakan uji chi square.

\section{HASIL PENELITIAN}

Karakteristik yang dimiliki tenaga kerja pada perusahaan produksi plastic Divisi Jumbo Bag dilihat dari umur, masa kerja dan tinggi badan dari tenaga kerja adalah sebagai berikut:

\section{a. Umur}

Tabel 1

DISTRIBUSI TENAGA KERJA MENURUT UMUR DI PERUSAHAAN PRODUKSI PLASTIK DIVISI JUMBO BAG TAHUN 2013

\begin{tabular}{cccc}
\hline No & Umur & Jumlah (orang) & Persentase (\%) \\
\hline 1 & $\leq 30$ tahun & 33 & 49,3 \\
\hline 2 & $>30$ tahun & 34 & 50,7 \\
\hline & Total & 67 & 100 \\
\hline
\end{tabular}

\section{b. Masa kerja}

Tabel 2

DISTRIBUSI TENAGA KERJA MENURUT MASA KERJA DI PERUSAHAAN PRODUKSI PLASTIK DIVISI JUMBO BAG TAHUN 2013

\begin{tabular}{cccc}
\hline No & Masa kerja & Jumlah (orang) & Persentase (\%) \\
\hline 1 & $\leq 5$ tahun & 27 & 40,3 \\
\hline 2 & $>5$ tahun & 40 & 59,7 \\
\hline & Total & 67 & 100 \\
\hline
\end{tabular}


ISSN 1693-3761

\section{c. Tinggi badan}

Tabel 3

DISTRIBUSI TENAGA KERJA MENURUT TINGGI BADAN DI PERUSAHAAN PRODUKSI PLASTIK DIVISI JUMBO BAG TAHUN 2013

\begin{tabular}{cccc}
\hline No & Tinggi badan & Jumlah (orang) & Persentase (\%) \\
\hline 1 & Pendek & 8 & 11,9 \\
\hline 2 & Standar & 10 & 14,9 \\
\hline 3 & Tinggi & 49 & 73,1 \\
\hline & Total & 67 & 100 \\
\hline
\end{tabular}

Tabel di atas menunjukan sebagian besar responden berumur diatas 30 tahun, dengan masa kerja diatas 5 tahun dan sebagian besar tenaga kerja memiliki postur tubuh yang tinggi . Hasil yang diperoleh tersebut dikaitkan dengan keluhan mosculoskeletal bahwa semakin lanjut usia maka keluhan yang dirasakan akan semakin nampak. Terdapat kecenderungan bahwa dengan kenaikan umur maka akan memperngaruhi keluhan musculoskeletal, hal ini dikarenakan semakin bertambahnya umur maka ketahanan tubuhnya akan semakin berkurang sehingga merasa cepat lelah. Ada pengaruh antara masa kerja dengan keluhan mosculoskeletal yang dirasakan tenaga kerja, karena ditinjau dari masa kerja semakin bertambah umur tenaga kerja, maka semakin lama pula tenaga kerja tersebut bekerja sehingga paparan dan tingkat kesehatan tenaga kerja akan semakin berkurang, sehingga keluhan mosculoskeletal akan dirasakan oleh tenaga kerja.

Tinggi badan juga mempengaruhi keluhan mosculoskeletal, hal ini dikarenakan jarak kursi dengan meja yang digunakan tidak sesuai dengan ukuran tubuh tenaga kerja, akibatnya keluhan musculoskeletal dirasakan oleh tenaga kerja. Kenyamanan tenaga kerja dalam bekerja dan melakukan aktivitas pekerjaanya, disesuaikan dengan ukuran tubuhnya, dengan ukuran yang tidak sesuai akan berpengaruh pada suatu keluhan mengingat tenaga kerja dalam melakukan pekerjaannya berada dalam posisi duduk dengan waktu yang sangat lama.

\section{Keluhan musculoskeletal}

Keluhan musculoskeletal yang dirasakan oleh tenaga kerja selama meiakukan aktivitas bekerja menjahit plastic jumbo bag selama delapan jam bekerja per hari

Tabel 4

DISTRIBUSI TENAGA KERJA MENURUT KELUHAN MOSCULOSKELETAL DI PERUSAHAAN PRODUKSI PLASTIK DIVISI JUMBO BAG TAHUN 2013

\begin{tabular}{ccccc}
\hline No & Keluhan mosculoskeletal & $\begin{array}{c}\text { Jumlah } \\
\text { (orang) }\end{array}$ & Tingkat keluhan & Persentase (\%) \\
\hline 1 & Kesemutan & 11 & Ringan & 16,4 \\
\hline 2 & Nyeri pinggang & 15 & Ringan & 22,4 \\
\hline 3 & Pegal bahu & 11 & Ringan & 16,4 \\
\hline 4 & $\begin{array}{c}\text { Nyeri pinggang dan } \\
\text { kesemutan }\end{array}$ & 7 & Sedang & 10,4 \\
\hline 5 & $\begin{array}{c}\text { Kesemutan dan pegal } \\
\text { bahu }\end{array}$ & 10 & Sedang & 14,9 \\
\hline 6 & $\begin{array}{c}\text { Pegal bahu dan nyeri } \\
\text { pinggang }\end{array}$ & 13 & Sedang & 19,4 \\
\hline 7 & Total & 67 & & 100 \\
\hline
\end{tabular}

Keluhan mosculoskeletal yang dirasakan tenaga kerja pada perusahaan produksi paslitik divisi jumbo bag sebagian besar mengeluh sakit nyeri pinggang ditandai rasa nyeri/ perasaan tidak nyaman pada tubuh bagian belakang dari rusuk sampai bagian bawah pantat dan nyambung kekaki. Tulang belakang manusia meliputi 33 ruas tulang dimana satu dengan lainnya saling terhubung terdiri atas tulang rawan, otot serta jaringan ikat. Sistem itu bekerja sama untuk mempertahankan tubuh. Salah satu factor dapat di sebabkan kelelahan otot yang menyebabkan tenaga kerja mengalami rasa nyeri pada otot, bisa juga tenaga kerja tersebut akan mengalami tremor, apabila tenaga kerja itu sudah mengalami lelah otot tidak menutup kemungkinan tenaga kerja akan mengalami lelah umum, dimana tenaga kerja tersebut akan mengalami kejenuhan sehingga hilangnya kemauan untuk bekerja, hal 
ini penyebabnya adalah kondisi psikis-psikologis

Ketetapan Depnaker, 2013).

pada tenaga kerja tersebut (Wagindikator,

Jarak Siku Tenaga Kerja ke Kursi yang Diguanakan

Tabel 5

DISTRIBUSI TENAGA KERJA MENURUT JARAK SIKU KE KURSI YANG DIGUNAKAN TENAGA KERJA DI PERUSAHAAN PRODUKSI PLASTIK DIVISI JUMBO BAG TAHUN 2013

\begin{tabular}{cccc}
\hline No & Jarak siku ke kursi & Jumlah (orang) & Persentase (\%) \\
\hline 1 & Tidak ergonomi & 60 & 89,6 \\
\hline 2 & Ergonomi & 7 & 10,4 \\
\hline & Total & 67 & 100 \\
\hline
\end{tabular}

Jarak siku tenaga kerja pada saat bekerja dengan kursi yang digunakan sebagian besar tidak ergonomis. Sarana tempat tenaga kerja bekerja dinyatakan ergonomi apabila tenaga kerja tersebut bekerja dengan posisi duduk yang memiliki sudut $90^{\circ}$ antara siku dengan meja yang digunakan, dimana dalam pengukurannya yang diukur yaitu jarak siku ke alas duduk yang digunakan oleh pekerja tersebut, hal ini perlu diperhatikan karena apabila jarak siku tidak sesuai dengan ketentuan maka akan mengakibatkan suatu keluhan yang nantinya akan dirasakan pada pekerja, mengingat pekerja di perusahaan produksi plastik divisi jumbo bag ini dalam melakukan pekerjaanya berada dalam posisi duduk selama 8 jam karena pekerjaan yang dilakukan adalah pekerjaan menjahit.

\section{Hubungan antara jarak siku ke kursi yang digunakan Tenaga Kerja dengan keluhan mosculoskeletal}

Tabel 6

DISTRIBUSI TENAGA KERJA MENURUT JARAK SIKU KE KURSI YANG DIGUNAKAN TENAGA KERJA DENGAN KELUHAN MOSCULOSKELETAL RESPONDEN DI PERUSAHAAN PRODUKSI PLASTIK DIVISI JUMBO BAG TAHUN 2013

\begin{tabular}{ccccccccc}
\hline \multirow{2}{*}{ No } & \multirow{2}{*}{$\begin{array}{c}\text { Jarak siku ke kursi } \\
\text { tempat bekerja }\end{array}$} & \multicolumn{3}{c}{ Tingkat keluhan } & \multicolumn{2}{c}{ Jumlah } \\
\cline { 3 - 8 } & & $\mathrm{n}$ & $\%$ & $\mathrm{n}$ & $\%$ & $\mathrm{~N}$ & $\%$ \\
\hline 1 & Tidak ergonomi & 30 & 50 & 30 & 50 & 60 & 100 \\
\hline 2 & Ergonomi & 6 & 85,7 & 1 & 14,3 & 7 & 100 \\
\hline
\end{tabular}

Tenaga kerja pada perusahaan produksi plastic devisi jumbo bag yang bekerja dengan kondisi jarak siku ke kursi yang digunakan tidak ergonomis menyatakan keluhan musculoskeletal. Dilihat dari uji chi square diketahui bahwa $\mathrm{p}<a$ $(0,079<0,10)$ yang artinya ada hubungan antara jarak siku ke kursi yang digunakan tenaga kerja dengan keluhan musculoskeletal, oleh karena itu dianjurkan pada pihak perusahaan untuk memberikan fasilitas yang

Tenaga kerja $50,7 \%$ berumur $>30$ tahun, 59,7\% memiliki masa kerja > 5 tahun, tinggi badan tenaga kerja $73,1 \%$ dalam kategori tinggi serta $60 \%$ memiliki jarak siku kurang atau lebih dari $35 \mathrm{~cm}$ dan $22,4 \%$ tenaga kerja mengalami keluhan nyeri pinggang, sedangkan hasil hubungan jarak siku responden dengan lebih memadahi seperti menyediakan kursi yang dapat diatur ketinggiannya sehingga pekerja dapat menyesuaikan sesuai dengan tingkat kenyamanannya, karena hal ini juga akan berpengaruh pada produktifitas dan kualitas hasil produksi yang nantinya akan dihasilkan oleh pekerja tersebut dan disarankan kepada tenaga kerja untuk rutin berolahraga.

\section{Kesimpulan}

keluhan mosculoskeletal, sebagian besar memiliki jarak siku tidak ergonomic, mengalami keluhan sedang dan ringan sebesar $50 \%$. Ada hubungan antara jarak siku ke kursi yang digunakan responden dengan keluhan mosculoskeletal. 
DAFTAR PUSTAKA

Andryani, 26 Desember 2012. Pengertian Kesemutan. http://id.shvoong.com/medicine-andhealth/epidemiology-publichealth/2345448-pengertian-kesemutan/. Diakses tanggal 14 Maret 2013 pukul 15.30

Nico dias, 4 Mei 2013. Pengertian ergonomi, apa dan bagaimana aplikasinya. http://www.coffeehideung.com/2013/05/ pengertian-ergonomi-apa-danbagaimana.html. Diakses tanggal 31 juli 2013 pukul 11.15

Notoadmojo, Soekidjo. 2010. Metodologi Penelitian Kesehatan. Jakarta : Rineka cipta

Nurmianto Eko, 1998, Ergonomi Konsep Dasar dan Apikasinya. Surabaya : prima printing

Santoso Gempur, 2004. Ergonomi Manusia, Peralatan dan Lingkungan. Sidoarjo : Prestasi Pustaka
Sastrowinoto Suyatno, 1985. Meningkatkan Produktivitas Dengan Ergonomi. Jakarta : PT. prtja

Suma'mur P.K, 2009,. Hygiene Perusahaan dan Keselamatan Kerja. Jakarta : Gunung Agung

Undang-undang Ketenagakerjaan oleh Presiden Republik Indonesia. 2013. Tentang Ketenagakerjaan.

http://www.slideshare.net/khairul fadli/u u-no-13-th-2003-ttg-ketenagakerjaan. Diakses tanggal 14 maret 2013 pukul 15.20

Wagindikator Foundation, 2013. Ketetapan depnaker.

http://www.gajimu.com/main/pekerjaanyanglayak/jam-kerja. Diakses tanggal 14 Maret 2013 pukul 15.50

www.infokesehatan.com, penyebab sakit pinggang, 6 Maret 2013

wWW.wikipedia.com, 6 Maret 2013 